\title{
Non-alcoholic fatty liver, adipose tissue, and the bone: a new triumvirate on the block
}

\author{
Giovanni Musso
}

Received: 2 May 2012/ Accepted: 5 July 2012/Published online: 18 July 2012

(C) Springer Science+Business Media, LLC 2012

In the latest years, a growing body of evidence has connected metabolic syndrome and obesity to bone loss and osteoporosis [1], thereby challenging the conventional view that excessive body weight protects against osteoporosis through increased mechanical load to the skeleton and enhanced cortical bone deposition [2]. In a parallel way, available data suggest that excess body weight may be detrimental to the skeleton, and that excessive adipose tissue plays a key role in this relationship [3]. Within this frame of research, recent studies focused on the relationship between bone health and non-alcoholic fatty liver (NAFLD), the hepatic manifestation of the metabolic syndrome, which recognizes in altered adipose tissue adipokine secretion a key pathogenic factor [4]. The two published studies on endocrine add importantly to the existing literature on the association between NAFLD and osteoporosis. First, ultrasonographic NAFLD was linked to low bone mass in a large cohort of Korean postmenopausal women, independently of age, BMI, smoking status, alcohol intake, and metabolic syndrome [5]. Second, the effect of a multidisciplinary weight-losing regimen on NAFLD, bone mineral density (BMD), and adipokine profile was assessed in post-puberal obese adolescents: weight loss improved NAFLD, BMD, insulin resistance, and plasma lipids. Importantly, bone mineral content changes were related to a reduction in insulin resistance and plasma leptin levels [6]. Consistent with these data, a recent crosssectional study, connected the histological severity of NAFLD to the degree of BMD changes in obese children [7].

G. Musso (ه)

Gradenigo Hospital, C.so Regina Margherita 8,

10132 Turin, Italy

e-mail: giovanni_musso@yahoo.it
Together with existing literature, these data strengthen the view that adipose tissue, the bone, and the liver are functionally interrelated organs and cooperate in regulating bone remodeling, glucose homeostasis, lipid and energy metabolism, through hormonal mediators that are only lately being unraveled (Table 1). As an example, insulin activates the osteoblast insulin receptor to increase bone formation and resorption and release of undercarboxylated osteocalcin into the systemic circulation, and adipose tissue-derived adipokines leptin and adiponectin can alter bone remodeling by either stimulating resorption or suppressing bone formation.

Reciprocally, the bone may be not only a target of visceral adipose tissue-released mediators, but also a metabolically active regulator of energy balance through the secretion of hormone and peptide signals, including undercarboxylated osteocalcin, a bone-specific secreted protein that enhances pancreatic $\beta$-cell viability and function, increases insulin and adiponectin secretion, and reduces fat mass and lipolysis [3, 8, 9] (Table 1). Perhaps the best evidence of the complex relationship between bone health and energy metabolism is provided by two lines of data: the first is represented by the experiments of Fulzele et al. [10], where mice harboring selective osteoblast deletion of the insulin receptor developed insulin resistance, obesity, fatty liver, and osteopenia, alterations that were all reversed by the administration of osteocalcin. The second line of evidence is exemplified by the thiazolidinedione (TZD) paradigm. TZDs are peroxisome proliferator-activated receptor(PPAR)- $\gamma$ agonists that effectively ameliorated liver histology, glycemic control, and insulin resistance in NASH and diabetes [11], but are associated with bone loss and increased risk of fractures, particularly in diabetic females $[12,13]$. In vitro studies demonstrated that PPAR- $\gamma$ agonists activators reallocate the fate of bone marrow 
Table 1 Main mediators of the hormonal loop between the bone, adipose tissue, the liver, and the pancreas

\begin{tabular}{|c|c|c|c|c|}
\hline Mediator & Source cell & Target cell & Biological action & Effect \\
\hline Insulin & $\begin{array}{c}\text { Pancreatic } \\
\beta \text {-cell }\end{array}$ & Osteoblast & $\begin{array}{l}\uparrow \text { Bone formation and resorption } \\
\uparrow \text { Undercarboxylated osteocalcin secretion }\end{array}$ & \\
\hline \multirow[t]{2}{*}{$\begin{array}{l}\text { Undercarboxylated } \\
\text { osteocalcin }\end{array}$} & Osteoblast & Pancreatic $\beta$-cells & $\uparrow \beta$-Cell viability and function & $\begin{array}{l}\text { Preserved insulin } \\
\text { secretion }\end{array}$ \\
\hline & & Adipocyte & $\uparrow$ Adiponectin secretion & $\begin{array}{l}\text { Increased insulin } \\
\text { sensitivity }\end{array}$ \\
\hline \multirow[t]{3}{*}{ Leptin } & Adipocyte & $\begin{array}{l}\text { Hypothalamic } \\
\text { ventro-medial } \\
\text { nucleus }\end{array}$ & $\begin{array}{l}\uparrow \beta \text {-Adrenergic sympathetic tone } \rightarrow \downarrow \text { osteoblast } \\
\text { proliferation and activity ( } \beta 2 \text { receptor-mediated) }\end{array}$ & Bone loss \\
\hline & & Osteoblast & $\uparrow$ Insulin-like growth factor binding protein (IGFBP)-2 & $\uparrow$ Insulin sensitivity \\
\hline & & Hepatic stellate cell & $\uparrow$ Activity and collagen deposition & $\uparrow$ Hepatic fibrogenesis \\
\hline \multirow[t]{6}{*}{ Adiponectin } & Adipocytes & Osteoblast & $\uparrow$ Osteoblast activity (paracrine action) & $\uparrow$ Bone deposition \\
\hline & & Hepatocyte & $\uparrow$ Fatty acid oxidation & $\downarrow$ Steatosis \\
\hline & & & $\uparrow$ Insulin sensitivity & \\
\hline & & & $\downarrow$ Fatty acid synthesis & \\
\hline & & & $\downarrow$ Cell apoptosis & $\begin{array}{l}\downarrow \text { Hepatic } \\
\text { necroinflammation }\end{array}$ \\
\hline & & Hepatic stellate cell & $\downarrow$ Activity and collagen deposition & $\downarrow$ Fibrogenesis \\
\hline \multirow[t]{5}{*}{ Vitamin D } & Diet skin & Pancreatic $\beta$-cells & $\uparrow \beta$-Cell viability and function & $\begin{array}{l}\text { Preserved insulin } \\
\text { secretion }\end{array}$ \\
\hline & & Hepatocytes & $\begin{array}{l}\text { Modulation of farnesoid X receptor (FXR) and liver X } \\
\text { receptor(LXR)- } \alpha \text { expression }\end{array}$ & $\begin{array}{l}\uparrow \text { Insulin sensitivity and } \\
\text { fatty acid oxidation }\end{array}$ \\
\hline & & & Modulation of cytochrome CYP7A1 expression & $\begin{array}{l}\text { Altered bile acid } \\
\text { homeostasis }\end{array}$ \\
\hline & & Hepatic stellate cells & $\downarrow$ Activity and collagen deposition & $\downarrow$ Fibrogenesis \\
\hline & & Adipocytes & $\begin{array}{l}\downarrow \text { Secretion of proinflammatory cytokines Interleukin } \\
\text { (IL)- } 1 \beta \text {, IL- } 6 \text {, tumor necrosis factor(TNF)- } \alpha\end{array}$ & $\downarrow$ Systemic inflammation \\
\hline
\end{tabular}

mesenchymal stem cells to adipocytes rather than to osteoblasts, eventually promoting bone marrow adiposity and bone loss, changes that spontaneously occur in diabetic animals $[14,15]$. The TZD paradigm clearly demonstrates that the tight connection between energy metabolism and skeletal remodeling begins early in the bone marrow, with lineage allocation of mesenchymal stem cells to adipocytes or osteoblasts, and highlights the need for a more complete understanding of energy utilization and skeletal remodeling to bring any potential agents into the future clinical armamentarium. While awaiting new molecular targets to be evaluated in preclinical studies, several considerations can be drawn from the few available human data and may guide current clinical practice. Interventions ameliorating liver disease, metabolic profile, and bone mineralization, including lifestyle-induced weight loss, should be encouraged and pursued as first-line treatments in all NAFLD patients [9]. Within lifestyle factors, increasing attention is being devoted to understand the role of nutritional deficiencies, including insufficient vitamin D intake, which is much more common than traditionally thought and is being associated to extraskeletal metabolic disorders, including obesity, diabetes, and NAFLD, independently of traditional risk factors [16-20]. The knowledge of the exact role and mechanisms whereby vitamin $\mathrm{D}$ and other oligoelements may affect intermediate metabolism and insulin sensitivity may lead to simple, feasible, and effective measures targeting both bone and metabolic health [21, 22].

Conflict of interest The author has no present or past conflict of interest to disclose.

\section{References}

1. D. von Muhlen, S. Safii, S.K. Jassal, J. Svartberg, E. BarrettConnor, Associations between the metabolic syndrome and bone health in older men and women: the Rancho Bernardo Study. Osteoporos. Int. 18, 1337-1344 (2007)

2. F.J.A. de Paula, M.C. Horowitz, C.J. Rosen, Novel insights into the relationship between diabetes and osteoporosis. Diabetes Metab. Res. Rev. 26, 622-630 (2010)

3. C.B. Confavreux, Bone: from a reservoir of minerals to a regulator of energy metabolism. Kidney Int. 79(Suppl 121), S14-S19 (2011)

4. G. Musso, R. Gambino, M. Cassader, G. Pagano, Meta-analysis: natural history of non-alcoholic fatty liver disease (NAFLD) and diagnostic accuracy of non-invasive tests for liver disease severity. Ann. Med. 43, 617-649 (2011) 
5. S.S. Moon, Y.S. Lee, S.W. Kim, Association of nonalcoholic fatty liver disease with low bone mass in postmenopausal women. Endocrine (2012). doi:10.1007/s12020-012-9639-6

6. R.M. Campos, A. de Piano, P.L. da Silva, J. Carnier, P.L. Sanches, F.C. Corgosinho et al., The role of pro/anti-inflammatory adipokines on bone metabolism in NAFLD obese adolescents: effects of long-term interdisciplinary therapy. Endocrine (2012). doi:10.1007/ s12020-012-9613-3

7. P.E. Pardee, W. Dunn, J.B. Schwimmer, Non-alcoholic fatty liver disease is associated with low bone mineral density in obese children. Aliment. Pharmacol. Ther. 35, 248-254 (2012)

8. K. Brochu-Gaudreau, C. Rehfeldt, R. Blouin, V. Bordignon, B.D. Murphy, M.F. Palin, Adiponectin action from head to toe. Endocrine 37, 11-32 (2010)

9. G. Mazziotti, J. Bilezikian, E. Canalis, D. Cocchi, A. Giustina, New understanding and treatments for osteoporosis. Endocrine 41, 58-69 (2012)

10. K. Fulzele, R.C. Riddle, D.J. Digirolamo, X. Cao, C. Wan, D. Chen et al., Insulin receptor signaling in osteoblasts regulates postnatal bone acquisition and body composition. Cell 142, 309-319 (2010)

11. G. Musso, M. Cassader, F. Rosina, R. Gambino, Impact of current treatments on liver disease, glucose metabolism and cardiovascular risk in non-alcoholic fatty liver disease (NAFLD): a systematic review and meta-analysis of randomised trials. Diabetologia 55, 885-904 (2012)

12. S.E. Kahn, S.M. Haffner, M.A. Heise, W.H. Herman, R.R. Holman, N.P. Jones et al., Glycemic durability of rosiglitazone, metformin, or glyburide monotherapy. N. Engl. J. Med. 355, 2427-2443 (2006)

13. T. Mancini, G. Mazziotti, M. Doga, R. Carpinteri, N. Simetovic, P.P. Vescovi et al., Vertebral fractures in males with type 2 diabetes treated with rosiglitazone. Bone 45, 784-788 (2009)
14. A.A. Ali, R.S. Weinstein, S.A. Stewart, A.M. Parfitt, S.C. Manolagas, R.L. Jilka, Rosiglitazone causes bone loss in mice by suppressing osteoblast differentiation and bone formation. Endocrinology 146, 1226-1235 (2005)

15. L.R. McCabe, Understanding the pathology and mechanisms of type 1 diabetic bone loss. J. Cell. Biochem. 102(6), 1343-1357 (2007)

16. M.L. Olson, N.M. Maalouf, J.D. Oden, P.C. White, M.R. Hutchison, Vitamin D deficiency in obese children and its relationship to glucose homeostasis. J. Clin. Endocrinol. Metab. 97(1), 279-285 (2012)

17. B.J. Boucher, Vitamin D insufficiency and diabetes risks. Curr. Drug Targets. 12, 61-87 (2011)

18. A. Birendinc, M. Abawi, M. Stepanova, A. Afendy, A. Baranova, Z. Goodman et al., Vitamin D may be protective against apoptosis in patients with nonalcoholic steatohepatitis (NASH). J. Hepatol. 56(S2), S501-S502 (2012)

19. M. Mahmud, I. Abdullah, R. Ghantous, J. Amer, Low vitamin D levels in nonalcoholic fatty liver disease associate with insulin resistance and liver injury progression via immune NK mechanisms. J. Hepatol. 56(S2), S503 (2012)

20. D. Kim, G.E. Chung, S.H. Lim, J.I. Yim, M.J. Park, Serum vitamin D is inversely associated with nonalcoholic fatty liver disease in general population. J. Hepatol. 56(S2), S511 (2012)

21. N.C. Bozkurt, E. Cakal, M. Sahin, E.C. Ozkaya, H. Firat, T. Delibasi, The relation of serum 25-hydroxyvitamin-D levels with severity of obstructive sleep apnea and glucose metabolism abnormalities. Endocrine 41, 518-525 (2012)

22. T. Nakano, Y.F. Cheng, C.Y. Lai, L.W. Hsu, Y.C. Chang, J.Y. Deng et al., Impact of artificial sunlight therapy on the progress of non-alcoholic fatty liver disease in rats. J. Hepatol. 55, 415-425 (2011) 